\title{
THE EFFICACY OF COUNSELLING IN GENERAL PRACTICE
}

\author{
David Lyon, General Practitioner, Castlefield HC, Runcorn \\ Frank Ledwith, Senior Lecturer, University College of St Martin, Lancaster
}

\begin{abstract}
SUMMARY
There is a large literature on the effectiveness of counsellors in general practice, but many reviews of that literature are partial and contradictory. To assess the effectiveness of one counsellor in one practice, a procedurally simple randomised trial was set up with 44 out of 87 patients referred given six counselling sessions, with the rest assigned to normal general practitioner (GP) treatment, without GPs being aware of the assignment. Measures of psychological distress at the outset and six months later suggested a substantial benefit for the counselling group and a reduction in rates of GP consultation, with some indication of a reduction in psychotropic medication.
\end{abstract}

\section{INTRODUCTION}

Is counselling effective in general practice? That would seem to be a simple question to answer. You might expect (and you would be right) that there is plenty of published research on the topic. A note of caution, however, is needed.

Busy practitioners are likely to look for reviews of literature rather than search out all the individual reports. These reviews are likely to come to very different conclusions. One recent review ${ }^{(1)}$, examining the prospect of a counsellor in every practice, advocated caution since it stated that "many attempts to evaluate effectiveness have shown little or no benefit".

Another review $^{(2)}$, however, showed mixed results with a good number of positive outcomes for counsellors and nurses. Yet another review, trying to separate effective and ineffective treatments ${ }^{(3)}$, suggests that "brief focussed psychotherapeutic approaches can be more cost-effective than drugs in the long term". Others ${ }^{(4)}$ have said that the "negative" results may often be due to long periods of follow-up in clinical trials where gains for the treated group reduce after one or two years. As was pointed out, if that were the sole criterion, then very few antibiotics would ever be deemed effective.

In some respects there may be simply too much published research on counselling since it has been $\operatorname{shown}^{(5)}$ that "psychotherapy is the most intensively investigated of all medical treatments in terms of the sheer number of trials" and "new outcome studies are appearing at the rate of 50 a month". There is ample opportunity for reviewers to choose the papers they quote to fit their own viewpoint, which sadly is the common practice. Such an approach is of course completely "unscientific". It is curious that reputable journals would reject any paper in which the researcher had selected which data to analyse, yet they accept such practice in reviews. There is a method, known as meta-analysis, which uses systemic criteria for selection of papers to review and formal methods for assessing the reliability of experimental effects. There is one such analysis of 500 papers on counselling $^{(6)}$ and one of specialist mental health interventions in general practice ${ }^{(7)}$. Both reviews report substantial benefits across all studies combined.

Some careful readers will by now be unhappy that the terms "counselling", "psychotherapy' and "psychological treatments" have been treated as identical, which they are not, though the distinctions are not easy to draw clearly. What is meant by counselling is varied, and so too are counsellors. Thus the question raised at the beginning needs to be rephrased: "Is the counselling offered in this practice effective?" That question can only be answered by a systemic study within the practice concerned, since the pattern of referrals to counsellor, community psychiatric nurse $(\mathrm{CPN})$ or psychiatrists will differ in different practices.

In addition, practices may differ in the criteria of success. Most research has concentrated on examining reductions in anxiety and depression but there is a growing interest in benefits related to costs. Accordingly we carried out a systemic trial of the effectiveness of a client-based counsellor who has worked in a general practice based in a health centre, with a largely white, working-class patient list. The reductions in stress, the rate of consulting of GPs and use of tranquillisers and anti-depressants were examined.

An audit in 1993/94 showed that the practice, with a patient list of 11,000 , had about 40,000 consultations per year with 142 referrals to the counsellor, 163 to CPNs, 20 to clinical psychologists and 20 to psychiatrists. Thus the referrals to psychiatrists were about $10 \%$ of the national $\operatorname{average}^{(8)}$.

It is important that the methods fit with the routine of a busy health centre and are credible to GPs. In the measurement of distress, the GPs agreed on 16 questions expressed in everyday language which covered the major complaints they heard from patients, which might suggest the need for a counsellor. The items included such questions as "how often do you worry?", "how well do you sleep?" and "how well do you see the future?" These were presented using a visual analogue scale (VAS), a line of $9.5 \mathrm{~cm}$ with appropriate words at each end to represent the extremes from "never" to "all the time", or "terrible" to "very good". Patients were asked to mark each of the 16 lines with an X at the appropriate point.

The self-completion questionnaire was handed by the receptionist to all patients on "control group" days. All those who were recommended for counselling on those days were followed up with a postal questionnaire six months later. Patients referred for counselling on other days of the recruitment period were given the questionnaire by the counsellor at the beginning of treatment and at the end. Six months later they were sent by post the questionnaire to fill in and return. To assess change, the position of the $\mathrm{X}$ was 
measured and compared with subsequent answers. Any change of less than one centimetre for a VAS was counted as zero. Any change greater than that was counted as one. Thus the best possible score would be +16 and the worst -16 . A person might score +7 and -3 for a net score of +4 .

Patients referred for counselling typically would be seen for six one-hour sessions every two weeks. Thus the total treatment period would be about 12 weeks. Information on prescriptions and rates of consultation was obtained from practice records for the six months prior to the initial consultation.

\section{RESULTS}

Over six months 87 patients were recommended for counselling by a GP. Of these 44 were assigned to the counsellor and 43 to a control group of usual general practice care with the GP not informed of the assignment. Subsequently five of the control group were referred for counselling and were therefore excluded from the study. There was some attrition of subjects' data as some people did not complete the follow-up questionnaires. As can be seen in the table below, over $75 \%$ of those referred were women, with the counselled group being somewhat younger, though this was not statistically significant.

Immediately after counselling was completed, the mean improvement score was 8.00, with 36 of the 39 (92\%) reporting an improvement. At six months follow-up (at least three months after counselling) the mean improvement score was 6.8 compared with 0.94 in the control group, which was statistically highly significant $(\mathrm{p}<0.001)$. Twenty-six out of 33 reported improvement compared with 20 out of 33 in the control group, which again was statistically highly significant $(\mathrm{p}<0.001)$. In the control group all but four of the changed scores lay in the range from -4 to +4 , indicating the normal rate of fluctuations, There were three people who reported improvements greater than +4 compared with 22 of the counselled group, a difference which is statistically significant $(\mathrm{p}<0.001)$. Four of the counselled group, however, were markedly worse on follow-up. Three of these spontaneously volunteered information on adverse events which had made life difficult for them. For one this may have been related to counselling, in that the patient finally plucked up the courage to break up a relationship.

The table shows that in both groups there was a reduction in mean consultation rates, expressed as yearly rates. In the counselled group the rate virtually halved, which was substantially and statistically significantly greater than in the control group.

\begin{tabular}{|c|c|c|c|}
\hline & $\begin{array}{l}\text { CONTROL } \\
\text { GROUP }\end{array}$ & $\begin{array}{l}\text { OUNSELLED } \\
\text { GROUP }\end{array}$ & $\begin{array}{l}\text { STATISTICAL } \\
\text { SIGNIFICANCE }\end{array}$ \\
\hline TOTAL & 33 & 38 & \\
\hline Women & 24 & 30 & \\
\hline Mean age & 45 & 41 & ns \\
\hline Men & 9 & 8 & \\
\hline Mean age & 51 & 35 & $\mathrm{~ns}$ \\
\hline \multicolumn{4}{|c|}{ TRANQUILLISERS } \\
\hline Before & 7 & 6 & \\
\hline After & 6 & 3 & - \\
\hline \multicolumn{4}{|c|}{ ANTI-DEPRESSANTS } \\
\hline Before & 0 & 3 & \\
\hline After & 8 & 4 & - \\
\hline \multicolumn{4}{|c|}{ CONSULTATION RATES } \\
\hline Before & 9.1 & 8.6 & \\
\hline After & 7.8 & 4.6 & $p<0.001$ \\
\hline
\end{tabular}

Table - Comparison of counselled and controlled group results
The number of patients being prescribed tranquillisers or anti-depressants was higher in the control group when comparing pre- and post-treatment periods. The numbers, however, are too small to be analysed statistically.

\section{DISCUSSION}

The results clearly show that, in this practice, the counselling offered produced short-term reductions in anxiety and depression and in rates of consulting the GPs. The data for prescriptions are interesting but would need much larger samples, probably five times as high, in order to generate reliable data for statistical analysis and allow detailed study of cost reductions.

The results only apply to one counsellor employed in one practice. It seems unlikely that the results are atypically good due to selection of less disturbed or more affluent patients: as noted above the practice refers few patients to psychiatrists and patients are largely white and working-class.

The methodology of the trial was not as rigorous as would be required by medical statisticians who would normally insist that patients are assigned to treatments individually after being entered into the trial and having completed the initial questionnaire. The use of consultation rates is useful as a relatively independent check on improvements due to counselling. Certainly the use of measures of change over time for each patient should help to reduce any bias in results due to different methods of administering the questionnaire, by the receptionist or counsellor. It is possible that the counselled group was inclined to give more positive replies in gratitude for the time and care of the counsellor but that will always be true for such trials since it is impossible to provide a placebo for counselling treatment: patients will always be aware of the treatment they have had. The postal follow-up produced good enough coverage and should have reduced the "personal gratitude" effect.

There are questions which will be pursued, using the same basic methodology, about the relative effectiveness of the highly experienced counsellor in comparison with trainees, since there is no clear evidence that greater experience in person-centred counselling leads to greater benefits ${ }^{(2)}$. There needs to be more work undertaken to explore the suggestion that counselling is particularly effective for those who are less seriously disturbed.

\section{REFERENCES}

1 Pringle $\mathbf{M}$, Laverty $\mathbf{J}$ A counsellor in every practice? $\mathrm{Br}$ Med J 1993;306:2-3

2 Corner, RH Counselling in general practice - does it work? J Roy Soc Med 1990;83:253-57

3 Marks I Unevaluated or inefficient approaches are hard to justify Br Med J 1994;309:1071-72

4 Ledwith F, Lyon D Patients' views ignored Br Med J 1994;309:412

5 Fonagy P Is there an answer to the outcome question? Changes 1995;13:168-77

6 Smith ML, Glass GV, Miller TI The benefits of psychotherapy Johns Hopkins 1980

7 Balestrieri M, Williams P, Wilkinson G Specialist mental health treatment in general practice: a meta-analysis Psychol Med 1988;18:711-17

8 Goldberg D, Huxley P Mental illness in the community London: Tavistock 1982 